Research Article

\title{
Profit Seeking versus Survival Seeking: Green Investment of Capital-Constrained Suppliers with Incentive Contracts
}

\author{
Bing Xia $\mathbb{D}^{1,2}$ and Junling Zhang $\mathbb{D}^{1,3}$ \\ ${ }^{1}$ Post-Doctoral Scientific Research Workstation, China Banking and Insurance Regulatory Commission, Beijing 100033, China \\ ${ }^{2}$ Business School, Renmin University, Beijing 100872, China \\ ${ }^{3}$ School of Finance, Tsinghua University, Beijing 100083, China
}

Correspondence should be addressed to Bing Xia; xiabin0721@126.com

Received 17 December 2020; Revised 13 May 2021; Accepted 25 May 2021; Published 17 June 2021

Academic Editor: Xiaobo Qu

Copyright (c) 2021 Bing Xia and Junling Zhang. This is an open access article distributed under the Creative Commons Attribution License, which permits unrestricted use, distribution, and reproduction in any medium, provided the original work is properly cited.

\begin{abstract}
This study explores a supply chain with a capital-constrained startup supplier who invests in product greenness and a manufacturer who sells green products to consumers under demand uncertainty. Green investment of the supplier is supported by the manufacturer with two incentive contracts: (i) investment- and (ii) revenue-sharing contracts. Profit- and survival-seeking objectives are considered for the startup supplier. Results show that the profit-seeking supplier increases its product greenness if demand uncertainty rises, whereas the survival-seeking supplier increases its product greenness if its capital constraints increase. Compared with the commonly used wholesale price contract, investment- and revenue-sharing contracts can help facilitate the "win-win" supply chain cooperation for improving product greenness. If the profit-seeking supplier cooperates with the manufacturer, the investmentsharing contract is preferred as the demand uncertainty increases. If a survival-seeking supplier cooperates with the manufacturer, the revenue-sharing contract is preferred as the capital constraint increases. Overall, the revenue-sharing contract is preferred given the high attractiveness of the green investment. By extending the discussion into two periods, the revenue-sharing contract will be preferred in the survival-seeking case because the cooperation can continue in a large parameter space.
\end{abstract}

\section{Introduction}

Product greenness expresses how environmentally friendly products are, and it always shows a positive correlation to consumers' purchasing decisions [1]. Thus, firms always take active measures to invest in green technologies and provide products with high greenness to establish market competitiveness $[2,3]$. Moreover, greenness will bring great competitiveness to the supply chain [4]. For example, General Motors has started the "green supply chain" program and induces its suppliers to implement 64 projects for improving green performance. However, green innovations are becoming expensive, especially in the automobile industry. In the early stage of the United States, automakers could meet the emission standards only by installing some emission control devices to automobiles. However, the standards have become stricter especially when the Level 3 standard is issued by 2014 [5]. Thus, automakers must invest in more innovative technologies and introduce products such as electric cars. These technologies are unaffordable to most suppliers, especially for the newly established suppliers that are short of capital. To support normal operations and green innovations, these startup suppliers always take on debts and might face bankruptcy risk while facing payment defaults $[6,7]$. Therefore, manufacturers always help to pay for the suppliers' green innovations. For example, Volkswagen invested $€ 20$ billion to CATL to improve its battery performance, and the GAC GROUP cooperates with the startup CATL for lithium battery and shares its long-term profits. Incentive measures can be classified as investment-sharing contract (one form of pay-before-performance contract) and revenue-sharing contract (one form of pay-after-performance contract) [8].

Choosing a proper incentive contract is difficult for the green supply chain, including capital-constrained startup 
suppliers, mainly because they may have different operational objectives. In China, approximately 20000 startups are formed every day in 2019; however, only less than $70 \%$ of them could survive past one year. That is, most startups fail, and only a small proportion of these firms show continuous developments and fewer of them finally go public [9]. Consequently, recent studies have proposed that startups may maximise their survival probability rather than expected profits in their operations [10-13]. Therefore, how green investment and contract choice in the supply chain will differ if the startup suppliers change their operational objective from profit seeking to survival seeking deserves further discussion.

Supply chain decisions are also affected by two other reasons, namely, demand uncertainty and capital constraint. On the basis of the study of CB insights [14], "no market need" and "running out of cash" are top-two reasons resulting in startup failures, which lead to the breakup of the supply chain cooperation. The influence of capital constraint on green investment has been previously introduced; however, the importance of demand uncertainty on green investment deserves further explanation. Consumers are sometimes cheated by some green products that cannot even meet the quality level of ordinary products. Thus, these consumers show little interest in product greenness, and firms face uncertainty about the market size of green products.

The fundamental aim of this study is to explore the answers to the following research issues:

(i) How will product greenness decisions differ when the capital-constrained supplier changes its objective from profit seeking to survival seeking?

(ii) What is the effectiveness of investment-sharing and revenue-sharing contracts on vertical $R \& D$ cooperation?

(iii) How will the manufacturer choose incentive contracts when its supplier changes its objectives?

(iv) How will product greenness decisions and contract choice differ when one-time cooperation is extended into a long-term one?

The above research questions are answered by improving traditional no-incentive analytical models and choosing two typical incentive contracts. This study investigates the impact of demand uncertainty, financial constraint, and two-period cooperation on the green supply chain cooperation. Literature has commonly assumed that all supply chain participants pursue profits in the business. However, in practice, a startup participant facing operational uncertainties and financial constraint pursues short-term survival more than profits. Consequently, the growing interests of the researchers are mentioned to explore characteristics of survival-seeking behaviours. Following this emerging research stream, this study introduces the survival-seeking objective into green supply chain management. Besides, sustainable cooperation is crucial to the green supply chain but rarely studied in the literature. Given this gap, this study develops the two-period cooperation model.

This paper is organised as follows: Section 2 presents the related literature. Section 3 presents the model and the two incentive contracts. By comparing the performance of different contracts, we provide some key propositions and show the contract choice in Section 4. Section 5 further discusses the contract choice by extending the cooperation into two periods. Section 6 provides management insights and offers conclusions.

\section{Literature Review}

This study focuses on the greenness decisions and contract choice in a green supply chain that includes a capitalconstrained startup supplier. This study is related to three streams of the literature, that is, green supply chain management (GSCM), green supply chain coordination by incentive contracts, and startup operational strategies under capital constraints.

2.1. GSCM. GSCM refers to the modern management model that considers environmental effect and resource efficiency in the supply chain, and it is always closely related to the concept of closed-loop supply chains, lean and agile supply chains, reverse logistics, and the practice of "just in time" [15]. The number of environmental innovations has increased in GSCM to reduce harmful substance contents and emissions along the supply chain. Most innovations have been integrated into final green products, and green product development has long been regarded as an important theme in GSCM [16]. Firms can design for environmental protection, design for recyclability, and conduct life cycle analysis to improve product greenness [17]. By promoting GSCM activities, firms can save cost-effectively and shape a good public image [18]. Feng et al. [19] indicated that GSCM practices will always lead to environmental and financial performance. Flammer [20] also found that firms adopting environmentally friendly practices are positively related to stock price increases, whereas firms adopting ecoharmful practices face stock price decreases. On this basis, the present study also focuses on the relationship between product greenness and firms' utilities. However, contributing to the GSCM literature, it investigates the relationship between product greenness and the firm's survival chance if capitalconstrained suppliers seek survival.

2.2. Green Supply Chain Coordination by Incentive Contracts. GSCM practices always come with large research and development $(\mathrm{R} \& \mathrm{D})$ investment and operational risk. Therefore, introducing incentive mechanisms into the GSCM field 
is necessary. The incentive mechanisms are explored from various perspectives, including intermediary intervention [21], strategic cooperation [22], incentive contracts [23, 24], and government incentives $[25,26]$. One of the most crucial directions is about environmental cooperation, and numerous economic models have been developed and discussed for green supply chain coordinating issues $[23,24,27-33]$. Ghosh and Shah [30] compare greenness decision and revenue in a decentralised supply chain and proposes that a two-part tariff contract can improve product greenness and coordinate the green supply chain. Furthermore, Ghosh and Shah [23] found that the cost-sharing contract can improve the greenness and revenues of manufacturers and retailers, whereas the bargaining mechanism will not increase the retailers' revenue. On the basis of a three-level decentralised green supply chain, Zhang and Liu [33] studied revenue-sharing mechanism, Shapley value coordination mechanism, and asymmetric Nash negotiation mechanism. They find that all mechanisms can improve the green performance in certain conditions. Dai et al. [28] analysed two typical cooperative behaviours by cartelisation and cost-sharing contract, and cartelisation is Pareto improving among the two under certain conditions. Besides, based on a two-period operational model, Dey and Saha [29] explored the influence of procurement decisions on product greenness. Under supply chain competition, Chakraborty et al. [27] examined the cost-sharing mechanism for improving product quality. Under financial constraint, Xing et al. [24] investigated how the green supply chain coordinates by investment-sharing contract. Considering cost learning effects, Yu et al. [32] compared the effectiveness of revenue- and cost-sharing contracts. Table 1 summarises these published studies on green supply chain coordination and highlights the contribution of the present study.

Table 1 shows that the green supply chain could be coordinated by different mechanisms, of which investmentsharing (cost-sharing) and revenue-sharing contracts are the most commonly studied. Compare how these widely used incentive contracts work when the supply chain faces demand uncertainty and financial constraint. Moreover, when considering these operational risks, the sustainability of cooperation should be given focus and the participants' utilities. However, existing literature fails to shed light on those issues. This study contributes to our understanding of the influence of financial constraint and demand uncertainty on sustainable green supply chain coordination.

\subsection{Capital-Constrained Startup Operational Strategies.} Generally, enterprises pursue profits in the short and long terms. However, the profit-seeking behaviours of these firms, especially startups, may be constrained by financial considerations [36]. Decision models that consider startup financial constraints and operations continue to grow in number [11,37-39]. Babich [40] argued that enterprises can make profits in the long term only if they survive in the market. Therefore, startups might be survival seeking rather than profit seeking upon entering new markets. More and more studies have begun to examine the survival-seeking behaviours of startups and employed two main methods for modelling their survival-seeking objective. Firstly, riskaverse utilities are used by some studies to rationalise survival-seeking behaviours [41, 42]. However, risk-averse utility suites established firms more because startups are not always risk-averse [39]. Moreover, this method does not consider capital constraints. When facing a capital constraint, smaller startups are exposed to bankruptcy or firm failure risks when their expected demand turns out to be low. Therefore, the objective of startups must fully consider the bankruptcy risk when they enter a new market. Accordingly, recent research assumes that survival-seeking startups maximise their assets or other financial measurements [10]. Based on the preceding assumption, the survival-seeking objective is introduced into fields of capacity investment [39], production quantity [43], quality competition [13], and so on. The current study contributes to this literature stream and firstly introduces the survival-seeking objective into GSCM. Particularly, this study establishes analytical models to (i) compare green supply chain decisions under profitand survival-seeking objectives and (ii) discuss the effects of capital constraints from the single enterprise level into the supply chain level.

\section{Model}

In this part, a baseline green supply chain structure with one startup supplier (denoted as " $s$ ") and one manufacturer (denoted as " $m$ ") is considered. The manufacturer transforms green components (or intermediate inputs) produced by the startup supplier into final products. Before presenting our model, we introduce some notations in Table 2.

Figure 1 presents the model timeline with three stages. Firstly, $t=1$; facing the demand uncertainty, the startup supplier and the manufacturer sign the contract. Three contracts are studied: (i) a wholesale price contract where the supplier determines the wholesale price $w$ and makes a take-it-or-leave-it offer to the manufacturer (benchmark); (ii) an investment-sharing contract where the manufacturer initially decides the proportion $\beta$ that he will share the supplier's green investment, and the supplier then determines the wholesale price $w$; and (iii) a revenue-sharing contract where the manufacturer initially decides the proportion $\delta$ that he will share its revenue with the startup supplier, and the wholesale price $w$ is then determined by the latter. Secondly, $t=2$; the capital-constrained supplier invests in product greenness into level $g$ and incurs the corresponding green investment $k g^{2}$. The unit production cost for the startup supplier is assumed to be zero. (This study mainly focuses on development-intensive green products, the core of which are normally new technologies that still need significant $\mathrm{R} \& \mathrm{D}$ effort and investment to be improved before being widely adopted. Examples of development-intensive green products include plug-in electric cars, solar power paper, and many other emerging technologies. For simplicity, we assume the variable manufacturing costs to be zero because for development-intensive products, such variable costs are insignificant compared with the fixed 
TABle 1: Comparison of existing models with the current study.

\begin{tabular}{|c|c|c|c|c|}
\hline Study & $\begin{array}{l}\text { Demand } \\
\text { uncertainty }\end{array}$ & $\begin{array}{l}\text { Financial } \\
\text { constraint }\end{array}$ & $\begin{array}{l}\text { Operational } \\
\text { period }\end{array}$ & Coordinating mechanisms \\
\hline Ghosh and Shah [30] & No & No & Single & Two-part tariff \\
\hline Zhang and Liu [33] & Yes & No & Single & $\begin{array}{c}\text { Revenue sharing; Shapley value method; asymmetric Nash } \\
\text { negotiation }\end{array}$ \\
\hline Ghosh and Shah [23] & No & No & Single & Cost sharing \\
\hline Dai et al. [28] & No & No & Single & $\begin{array}{l}\text { Cartelization } \\
\text { Cost sharing }\end{array}$ \\
\hline Dey and Saha [29] & No & No & Two & Cost sharing \\
\hline Taleizadeh et al. [34] & Yes & No & Single & $\begin{array}{l}\text { Cost sharing } \\
\text { Buyback }\end{array}$ \\
\hline Yang and Chen [35] & No & No & Single & $\begin{array}{c}\text { Cost sharing } \\
\text { Revenue sharing }\end{array}$ \\
\hline $\begin{array}{l}\text { Chakraborty et al. } \\
\text { [27] }\end{array}$ & No & No & Single & Cost sharing \\
\hline Xing et al. [24] & Yes & Yes & Single & Cost sharing \\
\hline Yu et al. [32] & No & No & Two & $\begin{array}{l}\text { Cost sharing } \\
\text { Revenue sharing }\end{array}$ \\
\hline Present study & Yes & Yes & Two & $\begin{array}{l}\text { Investment sharing } \\
\text { Revenue sharing }\end{array}$ \\
\hline
\end{tabular}

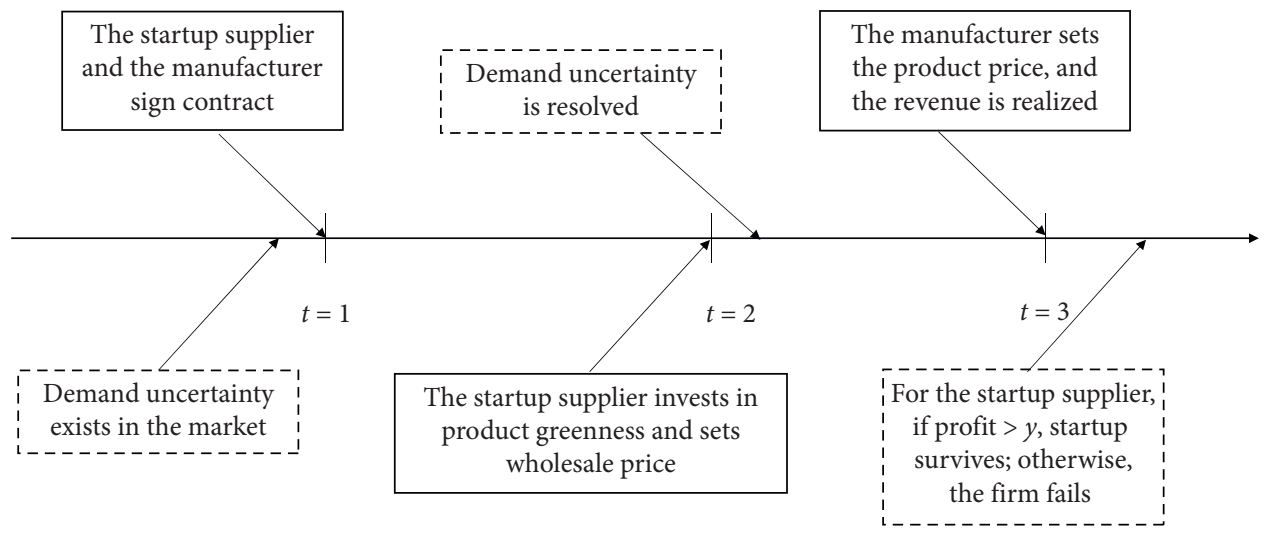

FIgURE 1: The sequence of events in the model line.

TABle 2: Notations.

\begin{tabular}{lc}
\hline Notation & Explanation \\
\hline$i$ & Index of firms, $i=s, m$ \\
$k$ & Greenness level, a decision variable of the startup supplier \\
$w$ & Unit cost of greenness improvement \\
$p$ & Wholesale price of the component determined by the startup supplier \\
$A$ & Price of the final product as a decision variable of the downstream \\
$b$ & Potential market size as a random variable, with $E(A)=a$ and variance $(A)=\sigma^{2}$ \\
$\delta$ & Demand responsiveness to the manufacturer's product greenness \\
$\beta$ & Proportion that the manufacturer shares its revenue to the supplier \\
$y$ & Proportion that the manufacturer shares to the supplier's green investment \\
$D$ & Survival threshold (minimum profit level) must be reached for the startup supplier \\
$\pi_{i}$ & Demand function of the manufacturer
\end{tabular}

costs of green innovation.) Finally, $t=3$; after the demand uncertainty is resolved (referring to the demand uncertainty, firms always make considerable market research. Price setting is a short-term market behaviour; thus, the manufacturer always changes its price according to the market reaction; that is, the manufacturer sets its 
price after the demand uncertainty is resolved), the product price is set, and revenues are realised.

From the definition of Banker et al. [44], we treat the quality-investing decision as a "demand-enhancing effort" in a nonaddress product differentiation model. Thus, the effects of price and quality on the demand are denoted as the integrated linear demand function, $D=A-p+b g$. That is, the manufacturer can increase the demand by decreasing its price or improving its product greenness. The manufacturer will optimise its utility by maximising its expected profit. However, decisions for the capital-constrained supplier are complicated because it might have different objectives. Under a profit-seeking objective, the capital-constrained supplier focuses on the expected profit and has the following utility function: $U=\max _{w, g} E\left[\pi_{s}\right]$. By contrast, under a survival-seeking objective, the utility of the supplier is closely related to the survival probability, with function $\psi=\max _{w, g} \operatorname{Pr}(\pi s \geq y)$. An important assumption is also raised.

Assumption 1. The survival threshold $y$ warrants a detailed discussion. Firstly, before the production and green investment, startups always need an upfront cash flow to recruit staff and rent land. They must repay these expenses once the revenue is generated. Otherwise, the startups will be forced to leave the industry [10]. Moreover, to support a sustainable growth, the startups will raise fund in more than one round; thus, the bank or venture capital will make their lending decisions based on a profit threshold. Both reasons lead to the assumption of $y$. As a target profit, $y$ can be influenced by competition, wage level, and economy of scale [12]. This variable will change between different stages and startups. For simplification, $y$ is taken as a constant in our model, whereas the analysis of a nonconstant $y$ can be extended similarly.

3.1. Wholesale Price Contract. The wholesale price contract is the most widely studied contract in the supply chain research [45]. Backward induction is adopted to obtain the equilibrium decisions and profits. In Stage 3, given the greenness level $g$ and the wholesale price $w$, the manufacturer's pricing problem can be expressed as follows:

$$
\pi_{M}(p)=(p-w)(A-p+b g) .
$$

Optimising equation (1) over $p$, the optimal product price can be obtained as follows:

$$
p^{*}(w)=\frac{(A+b g+w)}{2} .
$$

Substituting the manufacturer's price decision, the startup supplier's corresponding profit will be

$$
\pi_{S}=\frac{w(A+b g-w)}{2-k g^{2}} .
$$

The supplier then sets the wholesale price $w$ and the greenness level $g$ to maximise its utility. The supplier maximises $E\left(\pi_{S}\right)$ under a profit-seeking objective,

$$
E\left(\pi_{S}(w, g)\right)=\frac{w(a+b g-w)}{2-k g^{2}},
$$

while maximises $\operatorname{Pr}\left(\pi_{s} \geq y\right)$ under a survival-seeking objective,

$$
\operatorname{Pr}\left(\pi_{s}(w, g) \geq y\right)=\operatorname{Pr}\left(\frac{2\left(k g^{2}+y\right)}{w+w-b g} \leq A\right) .
$$

3.2. Investment-Sharing Contract. Banerjee and Lin [46] first discussed the theoretical framework of vertical R\&D cooperation in supply chains along with the R\&D investment-sharing mechanism. Investment-sharing agreements will rapidly promote innovative technologies, dissemination, and coverage and reduce entry barriers and mitigate investment risk [47]. Investment-sharing contracts can always encourage the green supply chain coordination in innovation-intensive industries effectively.

With an investment-sharing contract, the manufacturer initially sets $\beta$ in Stage 1 , which is the fraction of the green investment that he will bear. As $\beta$ increases, the startup supplier suffers fewer burdens of green improvement, which stimulates it to invest in higher product greenness. Once observing the proportion $\beta$, the startup initially invests in product greenness and then determines the wholesale price $w$ in Stage 2. In Stage 3, the manufacturer determines the selling price and generates revenue.

Backward induction is also utilised. The manufacturer's profit in Stage 3 is

$$
\pi_{M}=(p-w)(A-p+b g)-\beta k g^{2} .
$$

Optimising over $p$, the optimal product price is optimised as

$$
p^{*}(w, g, \beta)=\frac{(A+b g+w)}{2}
$$

3.2.1. Profit-Seeking Case. On the basis of equation (7), a profit-seeking supplier determines the optimal $s$ and $w$ to maximise its own profit, which can be expressed as follows:

$$
\pi_{S}=w(A-p+b g)-(1-\beta) k g^{2} .
$$

Under a profit-seeking objective, optimising $E\left(\pi_{s}\right)$ over $g$ and $w$ yields the following:

$$
\left(g^{*}(\beta), w^{*}(\beta)\right)=\left(\frac{a b}{8(1-\beta) k-b^{2}}, \frac{4 a(1-\beta) k}{8(1-\beta) k-b^{2}}\right) .
$$

Then, in stage 1 , on the basis of equation (9), the manufacturer determines the optimal investment share $\beta$ for the startup supplier for profit maximisation; that is,

$$
E\left(\pi_{M}(\beta)\right)^{*}=\frac{\left(4(1-\beta)^{2} k-\beta b^{2}\right) a^{2} k}{\left[b^{2}-8(1-\beta) k\right]^{2}}+\frac{\sigma^{2}}{4} .
$$

Then, the manufacturer's optimal $\beta$ under a profitseeking objective becomes 


$$
\beta_{p}^{*}=\frac{b^{2}}{(16 k)}
$$

Subsequently, the equilibrium wholesale price and profits can be obtained by including the investment-sharing proportion $\beta$ and the greenness level $g$ into equations (9) and (10).

3.2.2. Survival-Seeking Case. Under a survival-seeking objective, optimising $\operatorname{Pr}\left(\pi_{s} \geq y\right)$ over $g$ and $w$ yields the following:

$$
\left(g^{*}(\beta), w^{*}(\beta)\right)=\left(\sqrt{\frac{b^{2} y}{8(1-\beta)^{2} k^{2}-b^{2}(1-\beta) k}}, \sqrt{\frac{16(1-\beta) k y}{8(1-\beta) k-b^{2}}}\right) .
$$

Taking equation (12) into stage 1 , the manufacturer determines the optimal investment-sharing proposition $\beta$ to maximise its expected profit as follows:

$$
\beta_{s}^{*}=\arg \max _{\beta}\left(\frac{1}{4}\left(a+b^{2} \sqrt{\frac{y}{8(1-\beta)^{2} k^{2}-b^{2}(1-\beta) k}}-4 \sqrt{\frac{(1-\beta) k y}{8(1-\beta) k-b^{2}}}\right)^{2}-\frac{\beta k y b^{2}}{8(1-\beta)^{2} k^{2}-b^{2}(1-\beta) k}+\frac{\sigma^{2}}{4}\right) .
$$

The explicit solution of $\beta_{s}^{*}$ cannot be obtained. Thus, we can compare the investment-sharing values under different objectives by numerical calculations.

3.3. Revenue-Sharing Contract. In the supply chain research, the revenue-sharing contract is also an effective mechanism in coordinating the supply chain [48]. This contract is widely used in many cases. For example, platform distributors, such as Apple (iTunes) App Store, Google Play, and Windows Phone Store, always propose a consignment contract to app developers (that is, the suppliers, whose products significantly increase the product value of the platform distributors) based on a revenue-sharing policy [49]. In this part, the revenue-sharing contract is in a green supply chain with an endogenous upstream green innovation.

Similar to the investment-sharing contract, the manufacturer signs the revenue-sharing contract with the startup supplier before the supplier makes the green investment. Specifically, the manufacturer initially decides the proportion $\delta$ that he will share with the supplier. If $\delta$ increases, the supplier will be stimulated to increase product greenness. This problem can also be solved backwards. Starting from Stage 3, the manufacturer's profit can be expressed as follows:

$$
\pi_{M}=((1-\delta) p-w)(A-p+b g)
$$

The optimal product price is obtained as

$$
p=\frac{A+b g}{2}+\frac{w}{2(1-\delta)}
$$

Given the optimal price $p$, the startup supplier faces the profit with uncertainty, which can be expressed as follows:

$$
\pi_{s}=\left[\frac{\delta(A+b g)}{2}+\frac{2 w-\delta w}{2(1-\delta)}\right] \cdot\left[\frac{A+b g}{2}-\frac{w}{2(1-\delta)}\right]-k g^{2} .
$$

3.3.1. Profit-Seeking Case. A profit-seeking supplier determines the optimal $g$ and $w$ to maximise its expected profit, which can be expressed as

$$
E\left(\pi_{s}\right)=\left[\frac{\delta(a+b g)}{2}+\frac{2 w-\delta w}{2(1-\delta)}\right] \cdot\left[\frac{a+b g}{2}-\frac{w}{2(1-\delta)}\right]+\frac{\delta \sigma^{2}}{4}-k g^{2}
$$

Under a profit-seeking objective, optimising $E\left(\pi_{s}\right)$ over $g$ and $w$ yields

$$
\left(g^{*}(\delta), w^{*}(\delta)\right)=\left(\frac{a b}{4(2-\delta) k-b^{2}}, \frac{4(1-\delta)^{2} a k}{4(2-\delta) k-b^{2}}\right) .
$$

On the basis of equation (18), the manufacturer determines the optimal revenue share $\delta$ to maximise its expected profit as follows:

$$
E\left(\pi_{M}(\delta)\right)^{*}=\frac{4 a^{2}(1-\delta) k^{2}}{\left((4 \delta-8) k+b^{2}\right)^{2}}+\frac{(1-\delta) \sigma^{2}}{4} .
$$

Thus, the manufacturer's optimal $\delta_{p}^{*}$ under a profitseeking objective can also be obtained. However, given that the expression of $\delta_{p}^{*}$ is complicated, we examine how optimal revenue-sharing values under different objectives affect the vertical $R \& D$ cooperation by numerical calculation.

3.3.2. Survival-Seeking Case. Under a survival-seeking objective, the startup supplier maximises its survival probability by optimising $\operatorname{Pr}\left(\pi_{s} \geq y\right)$ over $g$ and $w$; that is,

$$
\left(g^{*}(\delta), w^{*}(\delta)\right)=\left(\sqrt{\frac{y b^{2}}{4 k^{2}(2-\delta)-k b^{2}}}, 4(1-\delta)^{2} \sqrt{\frac{y k}{4 k(2-\delta)-b^{2}}}\right) .
$$

Taking equation (20) into stage 1 , the manufacturer determines the optimal revenue share $\delta$ to maximise its survival probability, which can be expressed as follows: 


$$
\delta_{s}^{*}=\arg \max _{\delta}\left(\frac{1-\delta}{4} \cdot\left[a+\left(4 \delta-4+\frac{b^{2}}{k}\right) \cdot \sqrt{\frac{k y}{8 k-4 \delta k-b^{2}}}\right]^{2}+\frac{(1-\delta) \sigma^{2}}{4}\right)
$$

\section{Effectiveness of Incentive Contracts and Contract Choice in One-Period Cooperation}

Given the investment-sharing value $\beta$ and revenue-sharing value $\delta$, Proposition 1 summarises and presents equilibrium supply chain decisions, survival probabilities of startup supplier, and expected profits of the manufacturer. When the manufacturer cooperates with the profit-seeking supplier, the results under the investment-sharing contract, the wholesale price contract, and the revenue-sharing contract are denoted by subscripts PI, PW, and PR, respectively. By contrast, when the manufacturer cooperates with the survival-seeking supplier, the results under the investmentsharing contract, the wholesale price contract, and the revenue-sharing contract are denoted by subscripts SI, SW, and SR, respectively. Furthermore, for simplification, we define $z=b^{2} / k$ to represent the attractiveness of the green investment. Increasing $z$ implies that, under the same technical difficulty, investment on greenness will bring an increased demand.

Proposition 1. The supply chain decisions, survival probabilities of startup supplier, and expected profits of the manufacturer under the three different contracts are presented in Table 3, where $z=b^{2} / k$ is substituted into most mathematical expressions.

4.1. Effectiveness of Incentive Contracts on Greenness Improvement. By comparing all supply chain equilibriums, expected profits, and survival probabilities, some important propositions can be obtained.

Proposition 2. Given $\partial g_{P I}^{*} / \partial y=0, \partial w_{P I}^{*} / \partial y=0, \partial g_{P W}^{*} /$ $\partial y=0, \quad \partial w_{P W}^{*} / \partial y=0, \quad \partial g_{P R}^{*} / \partial y=0, \quad \partial w_{P R}^{*} / \partial y=0, \quad \partial g_{P I}^{*} /$ $\partial a>0, \partial w_{P I}^{*} / \partial a>0, \partial g_{P W}^{*} / \partial a>0, \partial w_{P W}^{*} / \partial a>0, \partial g_{P R}^{*} / \partial a>0$, $\partial w_{P R}^{*} / \partial a>0$, the operational decisions of the profit-seeking supplier are positively related to the market size. Given $\partial g_{S R}^{*} / \partial y>0, \partial w_{S R}^{*} / \partial y>0, \partial g_{S W}^{*} / \partial y>0, \partial w_{S W}^{*} / \partial y>0, \partial g_{S R}^{*} /$ $\partial y>0, \partial w_{S R}^{*} / \partial y>0, \partial g_{S I}^{*} / \partial a=0, \partial w_{S I}^{*} / \partial a=0, \partial g_{S W}^{*} / \partial a=0$, $\partial w_{S W}^{*} / \partial a=0, \partial g_{S R}^{*} / \partial a=0, \partial w_{S R}^{*} / \partial a=0$, the operational decisions of the survival-seeking supplier are positively related to the capital constraint.

Studying the operational decisions under the wholesale price contract, one may find that the wholesale price and the product greenness of the profit-seeking supplier increase with the market size; that is, a high market size encourages the supplier to make an investment. The supplier will improve the wholesale price to maintain the cash flow and support its investment. By contrast, the wholesale price and the product greenness of the survival-seeking supplier increase with the capital constraint. Hence, a stricter survival environment pushes the supplier to invest more in product greenness and focus on future growth. It is also supported by Zhang et al. [50], who found that green innovation can significantly reduce the financing constraints of enterprises. Thus, the profitseeking supplier focuses on the market size, whereas the survival-seeking supplier focuses on the survival probability. Moreover, if the consumers show a greater preference for the greenness ( $b$ increases), then high greenness becomes attractive and the startup supplier always improves the green investment; if the green innovation becomes difficult ( $k$ increases), the high greenness is costly and the startup supplier always reduces the investment on product greenness.

Proposition 2 is meaningful to the policy design. Since it is difficult to achieve rapid development only by relying on market forces, government intervention and regulation are needed [51]. The government normally offers pay-beforeperformance policies, such as direct funds, to support the startup R\&D investment and encourage the early development of new technologies (such as new energy technologies). Startups can relieve their financial pressure in the electric car market with the support of direct funds. However, as the survival-seeking startup green innovation is positively related to capital constraint, decreasing constraint might weaken their enthusiasm for high quality, which might damage consumer welfare. Thus, an increasing number of countries have been introducing pay-after-performance policies, such as subsidises, to promote electric cars.

Proposition 3. $A s \partial g_{P I}^{*} / \partial \beta>0, \partial g_{S I}^{*} / \partial \beta>0, \partial g_{P R}^{*} / \partial \delta>0$, and $\partial g_{S R}^{*} / \partial \delta>0$, investment- and revenue-sharing contracts stimulate the green innovation of the startup supplier.

To ensure that greenness decisions under different contracts and objectives are positive, we set $8(1-\beta)-z>0$, $8-z>0$, and $4(2-\delta)-z>0$. In comparison with the basic wholesale price contract, the startup supplier will improve the product greenness as the investment-sharing proposition $\beta$ and the revenue-sharing proposition $\delta$ increase. In other words, the incentive contracts have positive effects on the supply chain cooperation. By the investment-sharing contract, pressure from the investment on the product greenness is relieved and the startup supplier can produce more green products with a small cash flow. By the revenuesharing contract, a promise of future profit is given and the startup supplier is encouraged to improve green innovation, even if taking a bankruptcy risk. Notably, these positive effects will not change with the supplier's objectives.

Last but not least, in addition to the positive effects on stimulating green innovation, Proposition 4 also states that investment- and revenue-sharing contracts can lead to winwin cooperation between the manufacturer and the supplier under different objectives.

Proposition 4. In comparison with the wholesale price contract, the manufacturer can make a win-win cooperation with the startup supplier by investment- and revenue-sharing 


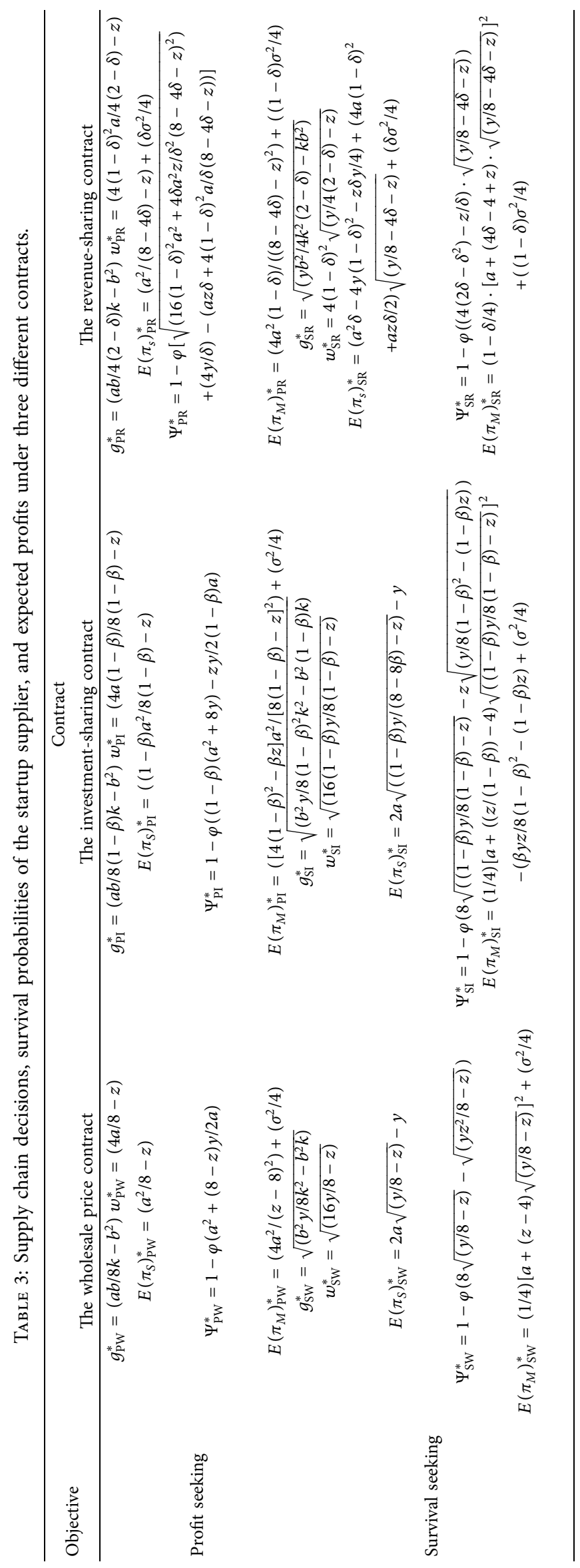


contracts. That is, there exists $\beta_{1}$, where $E\left(\pi_{S}\right)_{P I}^{*}\left(\beta=\beta_{1}\right)>$ $E\left(\pi_{S}\right)_{P W}^{*}$ and $E\left(\pi_{M}\right)_{P I}^{*}\left(\beta=\beta_{1}\right)>E\left(\pi_{M}\right)_{P W}^{*} ; \beta_{2}$, where $\Psi_{S I}^{*}\left(\beta=\beta_{2}\right)>\Psi_{S W}^{*}$ and $E\left(\pi_{M}\right)_{S I}^{*}\left(\beta=\beta_{2}\right)>E\left(\pi_{M}\right)_{S W}^{*} ; \delta_{1}$, where $E\left(\pi_{S}\right)_{P R}^{*}\left(\delta=\delta_{1}\right)>E\left(\pi_{S}\right)_{P W}^{*}$ and $E\left(\pi_{M}\right)_{P R}^{*}\left(\delta=\delta_{1}\right)>$ $E\left(\pi_{M}\right)_{P W}^{*}$; and $\delta_{2}$, where $E\left(\pi_{S}\right)_{S R}^{*}\left(\delta=\delta_{2}\right)>E\left(\pi_{S}\right)_{S W}^{*}$ and $E\left(\pi_{M}\right)_{S R}^{*}\left(\delta=\delta_{2}\right)>E\left(\pi_{M}\right)_{S W}^{*}$.

(a) Cooperate with the profit-seeking supplier by investment-sharing contract.

$\partial E\left(\pi_{S}\right)_{P I}^{*} / \partial \beta>0$ indicates that if the manufacturer improves the proposition of green investment, then the profit-seeking supplier can gain larger profits by improving green innovation. As the optimal sharing proposition is $\beta_{P I}^{*}=z / 16$, we can observe how the manufacturer's expected profit changes when it chooses the investment-sharing contract: $E\left(\pi_{M}\right)_{P I}^{*}-E\left(\pi_{M}\right)_{P W}^{*}>0 \Leftrightarrow 16-3 z>0$. Under the optimal proposition, $g_{P I}^{*}>0 \Leftrightarrow 16-3 z>0$. That is, the manufacturer's expected profit increases even if it bears more investment on greenness. Thus, $E\left(\pi_{S}\right)_{P I}^{*}\left(\beta=\beta_{P I}^{*}\right)>E\left(\pi_{S}\right)_{P W}^{*}$ and $E\left(\pi_{M}\right)_{P I}^{*}\left(\beta=\beta_{P I}^{*}\right)>E\left(\pi_{M}\right)_{P W}^{*}$ always hold.

(b) Cooperate with the profit-seeking supplier by revenuesharing contract.

$\partial E\left(\pi_{s}\right)_{P R}^{*} / \partial \delta>0$ implies that if the manufacturer shares more future revenues to the supplier, then the supplier will improve its green investment for a larger profit. At the same time, $\left(\partial E\left(\pi_{M}\right)_{P R}^{*} / \partial \delta\right)=$ $\left(4 a^{2}(z-4 \delta) /(z+8-4 \delta)^{3}\right)-\left(\sigma^{2} / 4\right)$. Given a small $\sigma, \partial E\left(\pi_{M}\right)_{P R}^{*} / \partial \delta>0$ when $\delta \longrightarrow 0$. Thus, there always exist $\delta$ that satisfies $E\left(\pi_{S}\right)_{P R}^{*}(\delta)>E\left(\pi_{S}\right)_{P W}^{*}$ and $E\left(\pi_{M}\right)_{P R}^{*}(\delta)>E\left(\pi_{M}\right)_{P W}^{*}$.

(c) Cooperate with the survival-seeking supplier by investment-sharing contract.

$\partial \Psi_{S I}^{*} / \partial \beta>0 \Leftrightarrow z<16(1-\beta)$. As $8(1-\beta)-z>0$, $\partial \Psi_{S I}^{*} / \partial \beta>0$ is satisfied. That is, if the manufacturer shares more green investment, then the startup supplier will have a larger survival probability by improving its product greenness.

The introduction of capital constraint y complicates the expressions. Thus, numerical computation is needed to explore how firms' utilities change with different contracts. Given $a=2.5, \sigma^{2}=0.2, y=0.1$, and $z=0.1$, there exists the optimal investment-sharing proportion $\beta^{*} \approx 0.75$, and $E\left(\pi_{M}\right)_{S I}^{*}>E\left(\pi_{M}\right)_{S W}^{*}$.

We can explore the advantage of investment-sharing contract as parameters $z$ and $y$ vary. Setting $a=2.5$ and $\sigma^{2}=0.2$, we compare $E\left(\pi_{M}\right)_{S I}^{*}$ and $E\left(\pi_{M}\right)_{S W}^{*}$ when parameters $z$ and $y$ vary. As indicated in Figure 2(a), when green innovation becomes attractive ( $z$ increases) or the capital constraint is small (y decreases), the manufacturer will obtain more profit if it chooses the investment-sharing contract rather than the wholesale price contract. (d) Cooperate with the survival-seeking supplier by revenue-sharing contract:

$\Psi_{S R}^{*}>\Psi_{S W}^{*} \Leftrightarrow(8-z) \sqrt{(y / 8-z)}>\left(8 \delta-4 \delta^{2}-z / \delta\right)$. $\sqrt{(y / 8-4 \delta-z)}, \quad$ as $\quad\left(8 \delta-4 \delta^{2}-z\right) / \delta$. $\sqrt{y /(8-4 \delta-z)}>\left(8 \delta-4 \delta^{2}-z \delta\right) / \delta . \quad$ Given $\sqrt{(y / 8-4 \delta-z)}=\sqrt{y(8-4 \delta-z)}$ and $(8-z) \sqrt{(y / 8-z)}=\sqrt{y(8-z)}>\sqrt{y(8-4 \delta-z)}$, $\Psi_{S R}^{*}>\Psi_{S W}^{*}$ always holds. Given $a=2.5$, $\sigma^{2}=0.2, y=0.3$, and $z=5$, there exists the revenuesharing proportion $\delta=0.5$, which makes $E\left(\pi_{M}\right)_{S R}^{*}(\delta)>E\left(\pi_{M}\right)_{S W}^{*}$.

We can also explore the advantage of revenue-sharing contract as parameters $z$ and $y$ vary. As shown in Figure 2(b), given parameters $a=2.5$ and $\sigma^{2}=0.2$, the revenue-sharing contract is optimal only when $z$ or the capital constraint $y$ is large. That is, when the supplier is forced to increase its green investment or green innovation is highly attractive, the revenue-sharing contract becomes dominant and the supply chain is coordinated.

4.2. Contract Choice in One-Period Cooperation. As analysed previously, investment- and revenue-sharing contracts can be used to stimulate green innovation and reach win-win cooperation. When cooperating with the startup supplier under different objectives, which improved contract will the manufacturer choose? The manufacturer is assumed to be concerned with its expected profit and improved product greenness. Given $a=2.5$, we explore the effects of demand uncertainty $\sigma$, capital constraint $y$, and attractiveness of green innovation $z$ on the supplier's green innovation and the manufacturer's expected profits.

Figure 3(a) shows the situation when the manufacturer cooperates with the profit-seeking supplier. In terms of improving the manufacturer's profits, the investment-sharing contract is more effective if green innovation is not attractive ( $z$ is small) or demand uncertainty $(\sigma)$ is large. However, the dominant space of investment-sharing contract is constrained by considering the manufacturer's profits and product greenness. For example, if $z<0.08$, then product greenness will be large under the revenue-sharing contract.

A large $z$ implies large rewards for the same investment on greenness. Both participants will allocate more attention to future profits if the investment is in line with high returns. The revenue-sharing contract works better in this situation because it mainly focuses on creating a larger share in the future market, whereas the investment-sharing contract focuses on alleviating short-term pressure from the cash flow. However, when the manufacturer cooperates with a profit-seeking supplier, increasing demand uncertainty indicates increased risk for the startup. High-greenness investment will still be maintained by the supplier. Revenue-sharing contract will only be chosen if the attractiveness of green innovation increases. That is, the dominant space of investment-sharing contract increases with the demand uncertainty. 


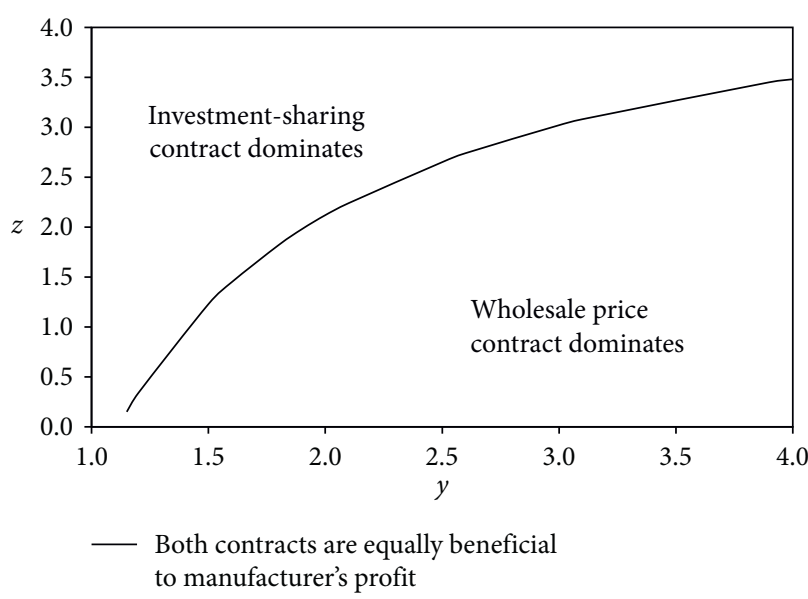

(a)

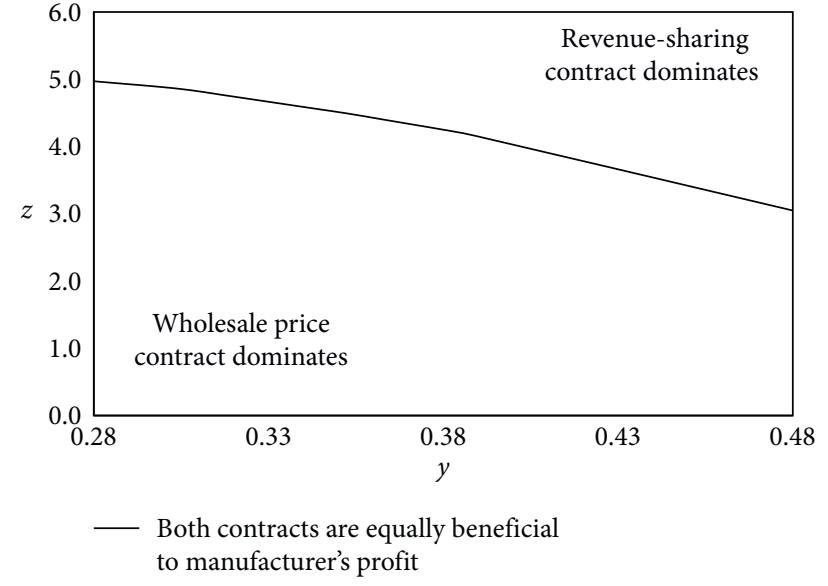

(b)

FIGURE 2: Feasibility of incentive contracts in cooperation with the survival-seeking startup supplier. (a) Feasibility of the investmentsharing contract. (b) Feasibility of the revenue-sharing contract.

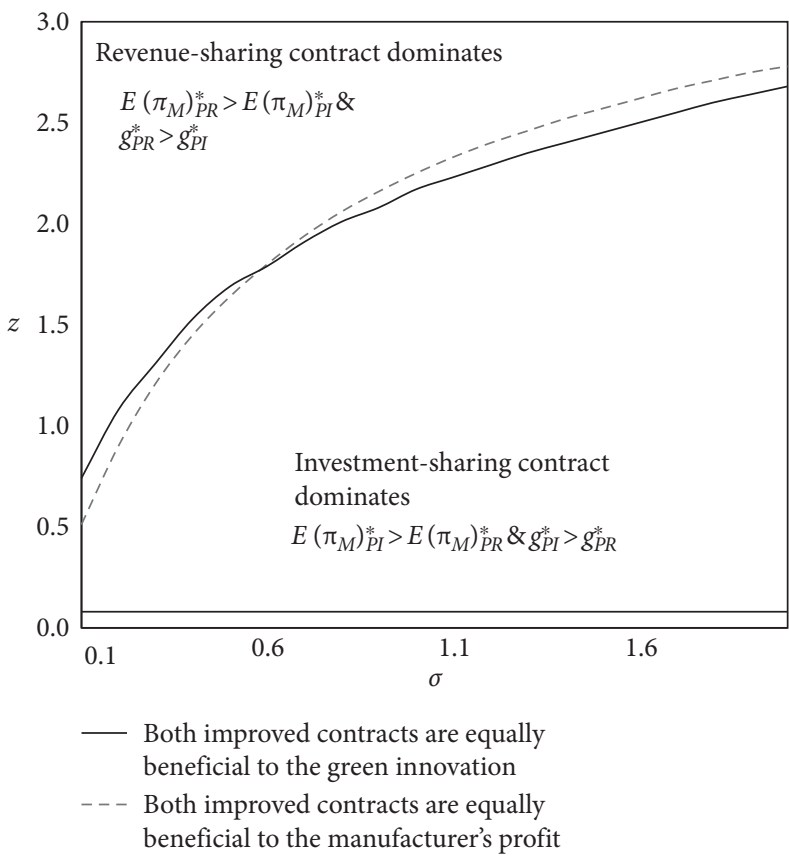

(a)

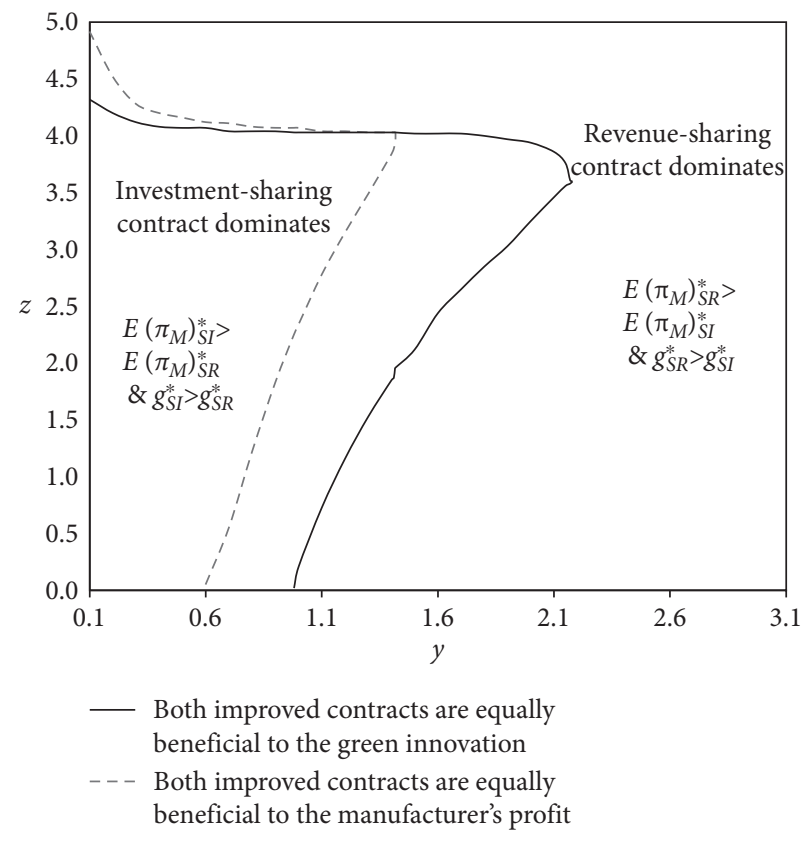

(b)

FIgURE 3: Contract choice in the one-period cooperation. (a) Cooperation with the profit-seeking supplier. (b) Cooperation with the survival-seeking supplier.

Figure 3(b) illustrates that when the manufacturer cooperates with the survival-seeking supplier, the revenuesharing contract will be used in a large parameter space to stimulate green innovation and improve the manufacturer's profit. Particularly, when the capital constraint increases to a certain level $(y>1.4)$, the survival-seeking supplier is forced to acquire high product greenness. Then, the manufacturer will find the revenue-sharing contract always dominant for higher profit. This result is also consistent with Proposition
2, which indicates that a larger capital constraint leads to higher greenness.

In the revenue-sharing contract, the survival-seeking supplier requires cash flow only for survival, which leaves sufficient revenue space for the profit-seeking manufacturer. Thus, if the startup supplier bears a larger capital constraint ( $y$ increases), it must improve its green innovation to create a larger revenue space. Then, the revenue-sharing contract becomes more beneficial for the supplier to reap profits. 
Lastly, as market shock $\sigma$ does not affect the greenness decision of the supplier, it does not obviously affect the contract choice of the manufacturer.

From the above results and discussion, we can obtain important management insights for the enterprise managers to choose proper incentive contracts in different industries. Figure 3 shows that the investment-sharing contract will be more suitable for the traditional industries, where the reward for green investment is relatively stable, such as clothing and furniture. For instance, Walmart has invested heavily in organic cotton procurement from its suppliers to introduce organic cotton clothing through its stores. In addition, Walmart mandates its suppliers to participate in carbon disclosure projects and primarily sources from suppliers who have undergone requisite environmental certifications.

In contrast, in industries where the attractiveness of green investment is high, the revenue-sharing contract will become dominant. This incentive mechanism is particularly suitable for the current smart electric vehicle industry because it has already shown its bright prospect these years. For example, in 2021, Huawei (an ICT solution provider) cooperated with BAIC (an automobile manufacturer) for the smart electric vehicle. Huawei has been investing heavily in advanced and safe self-driving technologies and will charge BAIC a certain proportion of profit per vehicle.

However, suppliers' characteristics and market risks could affect the dominance of revenue-sharing contracts in emerging industries. Cooperating with Volkswagen, CATL, a publicly listed startup company, pursues short-term survival but does not face obvious financial constraints. According to our results, investment-sharing would be suitable. Volkswagen directly invests $€ 20$ billion in CATL to improve its battery performance.

\section{Contract Choice in Two-Period Cooperation}

In this section, single-period cooperation is extended into twoperiod cooperation. In the above single-period cooperation, a manufacturer decides based solely on the current phase. However, a manufacturer may consider not only the current decision but also the future influence of the current decision. If the supplier goes bankrupt in the first period, then the manufacturer will not be able to find a substitute immediately and will consequently face supply bottlenecks. For example, under severe competition and weak external financing conditions in the emerging market, more than 16 mobile phone providers in China were forced into bankruptcy in just one year. This situation has caused huge damage to the mobile market. Thus, the manufacturer must consider the sustainability of cooperation when choosing stimulating contracts.

To compare the effectiveness of different contracts on stimulating sustainable cooperation, we describe the total profits of the manufacturer in two periods, as shown by the following profit function:

$$
U_{M}=U_{M 1}+\operatorname{Pr}\left(\pi_{S 1} \geq y\right) \cdot U_{M 2} .
$$

In the first period, the manufacturer cooperates with the startup supplier by one incentive contract. Product greenness is fixed in this period. The manufacturer will sustain the cooperation if the supplier survives the first period. In the second period, both participants will maximise their expected profits through a basic wholesale price contract. (Once the startup supplier survives the first period, it must have a larger survival probability in the next period. The startup supplier does not need to bear the green investment any longer and will share more revenue from improved greenness. Thus, we assume that the startup supplier also maximises the expected profit. On the basis of this assumption, we can jointly compare the effects of different incentive contracts on the green investment and bankruptcy risk of the supplier.) If the supplier goes bankrupt in the first period, then the manufacturer will miss the next selling season.

In the second period, the manufacturer and the startup supplier obtain the following profit: $\pi_{M 2}=\left(p_{2}-\right.$ $\left.w_{2}\right)\left(A-p_{2}+b g\right)$ and $\pi_{S 2}=w_{2}\left(A-p_{2}+b g\right)$. By derivation, the optimal selling price in Stage 2 is $p_{2}=\left(A+b g+w_{2} / 2\right)$. The expected profit of the supplier is $E\left(\pi_{S 2}\right)=\left(w_{2}\left(a+b g-w_{2}\right) / 2\right)$. Thus, the wholesale price is $w_{2}^{*}=(a+b g / 2)$, and the expected profit of the manufacturer in Stage 2 is $E\left(\pi_{M 2}\right)^{*}=\left((a+b g)^{2} / 16\right)+\left(\sigma^{2} / 4\right)$.

Taking the results in Table 2 into equation (22) and by examining the results under different objectives and contracts, we can obtain the improved product greenness (Figure 4), the survival probability of the startup supplier (Figure 5), and the total profits of the manufacturer (Figure 6). Following the above numerical analysis, we set $a=2.5, \sigma^{2}=0.2$ and $y=1$, unless otherwise stated.

In reality, the total profit of the manufacturer is determined by two competing forces. On the one hand, revenue realisations in both periods can be enhanced by greenness improvement. On the other hand, the manufacturer will only gain profit in one period if the cooperation breaks in the first period. These forces are closely related because the investment on greenness makes the startup supplier easily exposed to bankruptcy risk.

Comparing Figures 4 and 6, the priority orders of improved product qualities and total profit are nearly the same as in single-period cooperation in the profit-seeking case. In other words, as $z$ increases, the revenue-sharing contract is becoming more preferred. However, things have changed in the survival-seeking case. Given a small $z(z<2$ in Figure 6), the manufacturer can obtain a large profit by the revenuesharing contract even if improved greenness is low. The survival probability can explain this contradiction in Figure 5. Specifically, through the revenue-sharing contract, the survival-seeking supplier gains the largest survival probability in the cooperation. Proposition 5 is provided to support this key finding.

Proposition 5. If $z$ is relatively small and the manufacturer cooperates with the survival-seeking supplier, the revenuesharing contract will ensure the cooperation keeps into the second period in larger probability.

This proposition can be proven by comparing the survival probabilities $\Psi_{S I}^{*}$ and $\Psi_{S R}^{*}$. First, by formula deformation, 


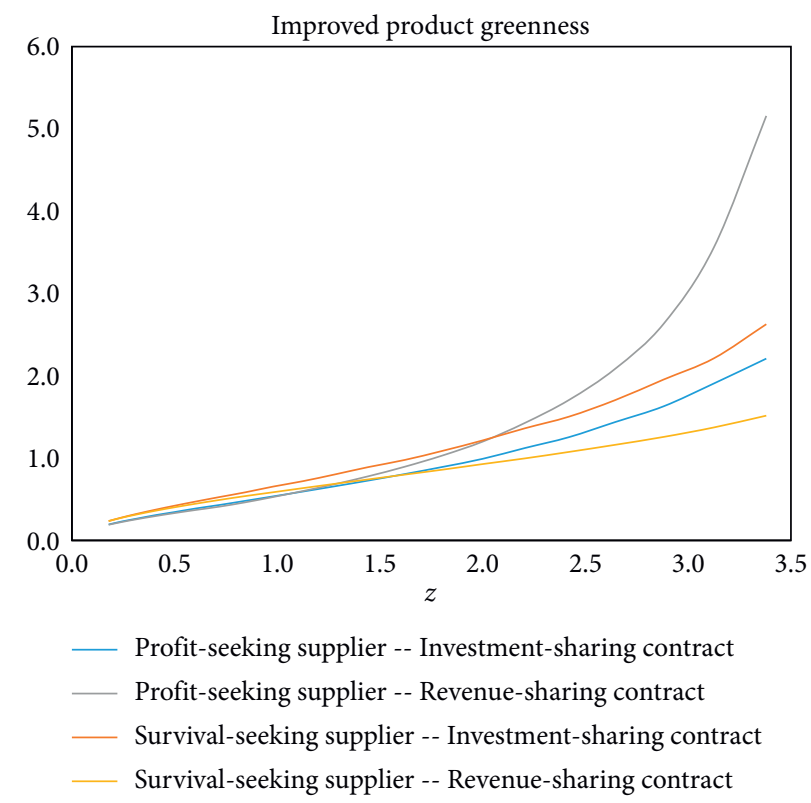

FIgURE 4: Improved product greenness.

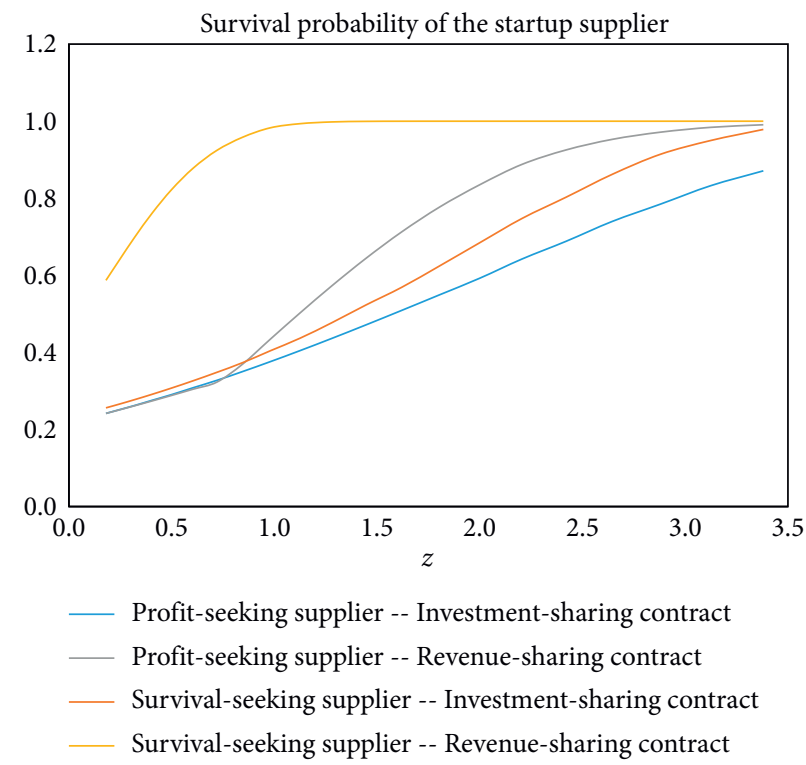

FIGURE 5: Survival probability of the supplier.

$\Psi_{\mathrm{SR}}^{*}=1-\varphi\left(\left(4\left(2 \delta-\delta^{2}\right)-z / \delta\right) \cdot \sqrt{(y / 8-4 \delta-z)}\right)>1-\varphi$ $\left(\left(8 \delta-4 \delta^{2}-\delta z / \delta\right) \cdot \sqrt{(y / 8-4 \delta-z)}\right)=1-\varphi(\sqrt{8-4 \delta-z}$ $\cdot \sqrt{y}), \quad$ and $\quad \Psi_{\mathrm{SI}}^{*}=1-\varphi(8 \sqrt{((1-\beta) y / 8(1-\beta)-z)}$ $\left.-z \cdot \sqrt{\left(y / 8(1-\beta)^{2}-(1-\beta) z\right)}\right)=1-\varphi((8-(z / 1-\beta))$. $\sqrt{(y / 8-(z / 1-\beta))})=1-\varphi(\sqrt{8-(z / 1-\beta)} \cdot \sqrt{y})$. If $8-$ $(z / 1-\beta)>8-4 \delta-z \Leftrightarrow((1 / 1-\beta)-1) z-4 \delta<0 \Leftrightarrow z<(4 \delta(1$ $-\beta) / \beta)$, then $\Psi_{\mathrm{SR}}^{*}>\Psi_{\mathrm{SI}}^{*}$. That is, given small $z$, the revenuesharing contract provides the participants a larger probability to keep long-term cooperation into the second period.

Therefore, if the manufacturer cooperates with the survivalseeking supplier, the revenue-sharing contract would benefit its long-term profitability. For instance, most suppliers of Tesla filed for bankruptcy in 2019. When Tesla cooperates with these 


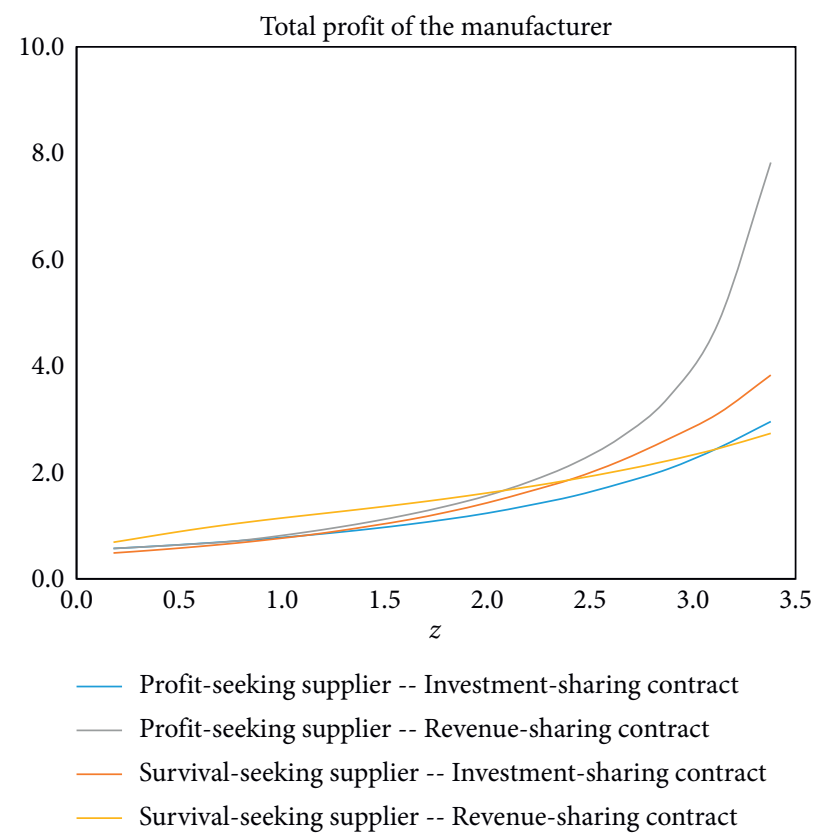

FIgURE 6: Total profit of the manufacturer in two-period cooperation.

Table 4: Key insights of the incentive contracts.

\begin{tabular}{|c|c|c|c|c|c|}
\hline \multirow[b]{2}{*}{$\begin{array}{l}\text { Incentive } \\
\text { contract }\end{array}$} & \multicolumn{2}{|c|}{ Incentive effect } & \multicolumn{2}{|c|}{ Applicable parameter space } & \multirow[b]{2}{*}{ Applicable scenarios } \\
\hline & One period & $\begin{array}{c}\text { Two } \\
\text { periods }\end{array}$ & Profit seeking & Survival seeking & \\
\hline $\begin{array}{l}\text { Investment- } \\
\text { sharing } \\
\text { contract }\end{array}$ & $\begin{array}{l}\text { Improved } \\
\text { greenness; win-win } \\
\text { cooperation }\end{array}$ & $\begin{array}{l}\text { Be less } \\
\text { preferred }\end{array}$ & $\begin{array}{l}\text { Low attractiveness of green } \\
\text { investment; demand } \\
\text { uncertainty increases }\end{array}$ & $\begin{array}{l}\text { Low attractiveness of green } \\
\text { investment; financial } \\
\text { constraint decreases }\end{array}$ & $\begin{array}{l}\text { Traditional industries, } \\
\text { including clothing and } \\
\text { furniture }\end{array}$ \\
\hline $\begin{array}{l}\text { Revenue- } \\
\text { sharing } \\
\text { contract }\end{array}$ & $\begin{array}{l}\text { Improved } \\
\text { greenness; win-win } \\
\text { cooperation }\end{array}$ & $\begin{array}{l}\text { Be more } \\
\text { preferred }\end{array}$ & $\begin{array}{l}\text { High attractiveness of green } \\
\text { investment; demand } \\
\text { uncertainty decreases }\end{array}$ & $\begin{array}{l}\text { High attractiveness of green } \\
\text { investment; financial } \\
\text { constraint increases }\end{array}$ & $\begin{array}{c}\text { Emerging industries, } \\
\text { including smart electric } \\
\text { vehicle and online APPs }\end{array}$ \\
\hline
\end{tabular}

bankruptcy-prone suppliers for green investment in electric vehicles, it can obtain the largest long-term profit by revenuesharing contract. Thus, even though the product greenness and short-term gain are relatively low, the suppliers can easily survive through the early period, which ensures the stability of the supply chain.

\section{Conclusions}

Designing incentive mechanisms to stimulate upstream green innovation, gain profits, and continue sustainable cooperation are key problems for manufacturers who wish to break its supply bottleneck and take their startup suppliers into the green supply chain. To solve these problems, we study two incentive contracts in a supply chain with endogenous green innovation by a capital-constrained startup supplier. Survivaland profit-seeking objectives are considered for the supplier. A model is developed to provide a risk-based justification of the optimal operating policy for the startup supplier by linking wholesale price with greenness decisions. Particularly, the survival probability of the supplier is considered as a measurement of the supplier's operational risks and the sustainability of long-term cooperation.
Managerially, our results reveal three key themes.

(a) Risk exposure in the green supply chain can be quantified.

Looking through our study, one may find that the survival probability of the startup supplier not only reflects the bankruptcy risk of the supplier but also the cooperation sustainability. Therefore, survival probability can be specified to quantify the risk exposure of the price and greenness decisions under capital constraint and demand uncertainty. Given the parameters of certain contracts, one should be able to use their ex ante assessments of market size $a$, allied uncertainty $\sigma$, capital constraint $y$, and cost of green innovation $k$ to quantify their risk exposure using Table 1.

(b) The operational objective of the startup supplier should be identified.

On the one hand, the operational decisions of the startup supplier under different objectives are entirely different. For example, as demonstrated by Proposition 2, the product greenness and the price decisions of the profit-seeking supplier are related to the market size, whereas those of the survival- 
seeking supplier are related to the capital constraint. These differences may be primarily attributed to the fact that profit-seeking startups take greenness improvement as an opportunity to divide profits from the increasing market share. By contrast, survivalseeking startups take greenness improvement as a method to ask for increased wholesale price and control bankruptcy risk.

On the other hand, no matter which type of supplier it cooperates with, the manufacturer should jointly consider the supplier's requirement of profit and its bankruptcy risk, because the bankruptcy risk of the startup measures the sustainability of two-period cooperation. Mostly, the manufacturer cannot gain the largest profit and the highest sustainability simultaneously. A large profit mainly results from a large investment on product greenness, which can easily break the cooperation. Thus, the manufacturer must identify the operational objective of the supplier before making operational decisions.

(c) Incentive contracts help facilitate revenue realisation and greenness improvement.

When cooperating with a capital-constrained startup supplier under demand uncertainty, the manufacturer may enlarge its own profit or improve product greenness by choosing different incentive contracts. In comparison with the wholesale price contract, the investment-sharing contract provides the startup supplier with an ex ante incentive by sharing its investment on greenness improvement, whereas the revenue-sharing contract provides the supplier with an ex post promise of revenue division. Our results confirm that the three aforementioned factors, namely, demand uncertainty $\sigma$, capital constraint $y$, and attractiveness of green innovation $z$ (defined by consumers' preference for greenness $b$ and cost of green innovation $k$ ), are intimately linked in the contract choice. The main insights of these two incentive contracts are summarized in Table 4.

In conclusion, our work helps in understanding the effects of various supply chain contracts on encouraging green innovation and increasing downstream firms' profits. We hope that our study will stimulate new avenues of research on supply chain contracts and product innovation in supply chains. Nevertheless, this study still has some limitations. This study focuses on upstream green innovation; however, green investment can also be made by manufacturers in some cases. Incorporating downstream and upstream green innovation decisions can engender several new interesting research questions. These issues are beyond the scope of this study. Thus, we leave them for future research.

\section{Data Availability}

All data used to support the findings of this study are available within the article.

\section{Conflicts of Interest}

The authors declare no conflicts of interest.

\section{Acknowledgments}

This work was supported by the China Postdoctoral Science Foundation (2020M670588).

\section{References}

[1] R. M. Dangelico and P. Pontrandolfo, "From green product definitions and classifications to the green option matrix," Journal of Cleaner Production, vol. 18, no. 16-17, pp. 16081628, 2010.

[2] J. S. Golden, V. Subramanian, and J. B. Zimmerman, "Sustainability and commerce trends," Journal of Industrial Ecology, vol. 15, no. 6, pp. 821-824, 2011.

[3] F. Pan, B. Xi, and L. Wang, "Environmental regulation strategy analysis of local government based on evolutionary game theory," in Proceedings of the 21th Annual Conference 2014 International Conference on Management Science \& Engineering, pp. 1957-1964, IEEE, Helsinki, Finland, August 2014.

[4] W. Zhu and Y. He, "Green product design in supply chains under competition," European Journal of Operational Research, vol. 258, no. 1, pp. 165-180, 2017.

[5] EPA, "Control of air pollution from motor vehicles: tier 3 motor vehicle emission and fuel standards," Technical Report, Environmental Protection Agency, Washington, DC, USA, 2014.

[6] L. Fang and S. Xu, "Financing equilibrium in a green supply chain with capital constraint," Computers \& Industrial Engineering, vol. 143, Article ID 106390, 2020.

[7] G. C. Reid, "Complex actions and simple outcomes: how new entrepreneurs stay in business," Small Business Economics, vol. 13, no. 4, pp. 303-315, 1999.

[8] G. Liu, H. Yang, and R. Dai, "Which contract is more effective in improving product greenness under different power structures: revenue sharing or cost sharing?" Computers \& Industrial Engineering, vol. 148, Article ID 106701, 2020.

[9] Z. J. Acs and C. Armington, Endogenous Growth and Entrepreneurial Activity in Cities, Center for Economic Studies, Bureau of the Census, Washington, DC, USA, 2003.

[10] T. W. Archibald, L. C. Thomas, J. M. Betts, and R. B. Johnston, "Should start-up companies be cautious? Inventory policies which maximise survival probabilities," Management Science, vol. 48, no. 9, pp. 1161-1174, 2002.

[11] F. Tanrısever, S. S. Erzurumlu, and N. Joglekar, "Production, process investment, and the survival of debt-financed startup firms," Production and Operations Management, vol. 21, no. 4, pp. 637-652, 2012.

[12] M. M. Wei, T. Yao, B. Jiang, and S. T. Young, "Profit seeking vs. survival seeking: an analytical study of supplier's behavior and buyer's subsidy strategy," Production and Operations Management, vol. 22, no. 2, pp. 269-282, 2013.

[13] B. Xia, J. E. Guo, and R. Y. K. Fung, "Quality investment timing by the startup and the established firm," Managerial and Decision Economics, vol. 39, no. 3, pp. 275-284, 2018.

[14] CB Insights, "The top 20 reasons startups fail," 2014, https:// www.cbinsights.com/blog/startup-failure-reasons-top/.

[15] K. Mathu, "Green supply chain management: a precursor to green purchasing," in Green Practices and Strategies in Supply Chain ManagementIntechOpen, London, UK, 2019.

[16] R. Wilding, B. Wagner, A. Ashby, M. Leat, and M. HudsonSmith, "Making connections: a review of supply chain management and sustainability literature," Supply Chain 
Management: An International Journal, vol. 17, no. 5, pp. 497-516, 2012.

[17] S. Kara, S. Ibbotson, and B. Kayis, "Sustainable product development in practice: an international survey," Journal of Manufacturing Technology Management, vol. 25, no. 6, pp. 848-872, 2014.

[18] J. D. Wisner, K. C. Tan, and G. K. Leong, Principles of Supply Chain Management: A Balanced Approach, Thomson SouthWestern, Mason, OH, USA, 2012.

[19] M. Feng, W. Yu, X. Wang, C. Y. Wong, M. Xu, and Z. Xiao, "Green supply chain management and financial performance: the mediating roles of operational and environmental performance," Business Strategy and the Environment, vol. 27, no. 7, pp. 811-824, 2018.

[20] C. Flammer, "Corporate social responsibility and shareholder reaction: the environmental awareness of investors," Academy of Management Journal, vol. 56, no. 3, pp. 758-781, 2013.

[21] I. E. Nielsen, S. Majumder, and S. Saha, "Exploring the intervention of intermediary in a green supply chain," Journal of Cleaner Production, vol. 233, pp. 1525-1544, 2019.

[22] I. Nielsen, S. Majumder, E. Szwarc, and S. Saha, "Impact of strategic cooperation under competition on green product manufacturing," Sustainability, vol. 12, no. 24, Article ID 10248, 2020.

[23] D. Ghosh and J. Shah, "Supply chain analysis under green sensitive consumer demand and cost sharing contract," International Journal of Production Economics, vol. 164, pp. 319-329, 2015.

[24] G. Xing, B. Xia, and J. Guo, "Sustainable cooperation in the green supply chain under financial constraints," Sustainability, vol. 11, no. 21, p. 5977, 2019.

[25] I. E. Nielsen, S. Majumder, S. S. Sana, and S. Saha, "Comparative analysis of government incentives and game structures on single and two-period green supply chain," Journal of Cleaner Production, vol. 235, pp. 1371-1398, 2019.

[26] S. Saha, S. Majumder, and I. E. Nielsen, "Is it a strategic move to subsidized consumers instead of the manufacturer?" IEEE Access, vol. 7, pp. 169807-169824, 2019.

[27] T. Chakraborty, S. S. Chauhan, and M. Ouhimmou, "Costsharing mechanism for product quality improvement in a supply chain under competition," International Journal of Production Economics, vol. 208, pp. 566-587, 2019.

[28] R. Dai, J. Zhang, and W. Tang, "Cartelization or Cost-sharing? Comparison of cooperation modes in a green supply chain," Journal of Cleaner Production, vol. 156, pp. 159-173, 2017.

[29] K. Dey and S. Saha, "Influence of procurement decisions in two-period green supply chain," Journal of Cleaner Production, vol. 190, pp. 388-402, 2018.

[30] D. Ghosh and J. Shah, "A comparative analysis of greening policies across supply chain structures," International Journal of Production Economics, vol. 135, no. 2, pp. 568-583, 2012.

[31] S. Swami and J. Shah, "Channel coordination in green supply chain management," Journal of the Operational Research Society, vol. 64, no. 3, pp. 336-351, 2013.

[32] B. Yu, J. Wang, X. Lu, and H. Yang, "Collaboration in a lowcarbon supply chain with reference emission and cost learning effects: cost sharing versus revenue sharing strategies," Journal of Cleaner Production, vol. 250, Article ID 119460, 2020.

[33] C.-T. Zhang and L.-P. Liu, "Research on coordination mechanism in three-level green supply chain under noncooperative game," Applied Mathematical Modelling, vol. 37, no. 5, pp. 3369-3379, 2013.

[34] A. A. Taleizadeh, N. Alizadeh-Basban, and B. R. Sarker, "Coordinated contracts in a two-echelon green supply chain considering pricing strategy," Computers \& Industrial Engineering, vol. 124, pp. 249-275, 2018.

[35] H. Yang and W. Chen, "Retailer-driven carbon emission abatement with consumer environmental awareness and carbon tax: revenue-sharing versus cost-sharing," Omega, vol. 78, pp. 179-191, 2018.

[36] B. C. Greenwald and J. E. Stiglitz, Asymmetric Information and the New Theory of the Firm: Financial Constraints and Risk Behavior (No. W3359), National Bureau of Economic Research, Cambridge, MA, USA, 1990.

[37] J. A. Buzacott and R. Q. Zhang, "Inventory management with asset-based financing," Management Science, vol. 50, no. 9, pp. 1274-1292, 2004.

[38] N. R. Joglekar and M. Lévesque, "Marketing, R\&D, and startup valuation," IEEE Transactions on Engineering Management, vol. 56, no. 2, pp. 229-242, 2009.

[39] R. Swinney, G. P. Cachon, and S. Netessine, "Capacity investment timing by start-ups and established firms in new markets," Management Science, vol. 57, no. 4, pp. 763-777, 2011.

[40] V. Babich, "Dealing with supplier bankruptcies: costs and benefits of financial subsidies," in Proceedings of the 2007 International Conference on Manufacturing and Service Operations Management, Ann Arbor, MI, USA, 2007.

[41] J. A. Van Mieghem, "Commissioned paper: capacity management, investment, and hedging: review and recent developments," Manufacturing \& Service Operations Management, vol. 5, no. 4, pp. 269-302, 2003.

[42] M. R. Walls and J. S. Dyer, "Risk propensity and firm performance: a study of the petroleum exploration industry," Management Science, vol. 42, no. 7, pp. 1004-1021, 1996.

[43] M. Lévesque, X. Zhao, and J. Bian, "Competitive interplay of production decisions: rivalry between established and startup firms," IEEE Transactions on Engineering Management, vol. 65, no. 1, pp. 85-98, 2017.

[44] R. D. Banker, I. Khosla, and K. K. Sinha, "Quality and competition," Management Science, vol. 44, no. 9, pp. 1179-1192, 1998.

[45] M. A. Lariviere and E. L. Porteus, "Selling to the newsvendor: an analysis of price-only contracts," Manufacturing \& Service Operations Management, vol. 3, no. 4, pp. 293-305, 2001.

[46] S. Banerjee and P. Lin, "Vertical research joint ventures," International Journal of Industrial Organization, vol. 19, no. 12, pp. 285-302, 2001.

[47] V. M. Ribeiro, "Exclusion and regulatory intervention in investment sharing agreements," Telecommunications Policy, vol. 40, no. 10-11, pp. 1032-1051, 2016.

[48] G. P. Cachon and M. A. Lariviere, "Supply chain coordination with revenue-sharing contracts: strengths and limitations," Management Science, vol. 51, no. 1, pp. 30-44, 2005.

[49] J. S. Gans, "Mobile application pricing," Information Economics and Policy, vol. 24, no. 1, pp. 52-59, 2012.

[50] Y. Zhang, C. Xing, and Y. Wang, "Does green innovation mitigate financing constraints? Evidence from China's private enterprises," Journal of Cleaner Production, vol. 264, Article ID 121698, 2020.

[51] M. Song, Q. Xie, S. Wang, and H. Zhang, "Could environmental regulation and $\mathrm{R} \& \mathrm{D}$ tax incentives affect green product innovation?" Journal of Cleaner Production, vol. 258, Article ID 120849, 2020. 